Article

\title{
Constructal Design of an Arrow-Shaped High Thermal Conductivity Channel in a Square Heat Generation Body
}

\author{
Fengyin Zhang ${ }^{1,2,3}$, Huijun Feng ${ }^{1,2}$, Lingen Chen ${ }^{1,2, *(\mathbb{D}}$, Jiang You ${ }^{1,2,3} \mathbb{D}$ and Zhihui Xie ${ }^{1,2,3}$ \\ 1 Institute of Thermal Science and Power Engineering, Wuhan Institute of Technology, Wuhan 430205, China; \\ zfy1125546402@163.com (F.Z.); huijunfeng@139.com (H.F.); jsjdyoujiang@163.com (J.Y.); \\ 15071081343@163.com (Z.X.) \\ 2 School of Mechanical \& Electrical Engineering, Wuhan Institute of Technology, Wuhan 430205, China \\ 3 College of Power Engineering, Naval University of Engineering, Wuhan 430033, China \\ * Correspondence: lgchenna@yahoo.com or lingenchen@hotmail.com
}

Received: 24 March 2020; Accepted: 16 April 2020; Published: 20 April 2020

\begin{abstract}
A heat conduction model with an arrow-shaped high thermal conductivity channel (ASHTCC) in a square heat generation body (SHGB) is established in this paper. By taking the minimum maximum temperature difference (MMTD) as the optimization goal, constructal designs of the ASHTCC are conducted based on single, two, and three degrees of freedom optimizations under the condition of fixed ASHTCC material. The outcomes illustrate that the heat conduction performance (HCP) of the SHGB is better when the structure of the ASHTCC tends to be flat. Increasing the thermal conductivity ratio and area fraction of the ASHTCC material can improve the HCP of the SHGB. In the discussed numerical examples, the MMTD obtained by three degrees of freedom optimization are reduced by $8.42 \%$ and $4.40 \%$, respectively, compared with those obtained by single and two degrees of freedom optimizations. Therefore, three degrees of freedom optimization can further improve the HCP of the SHGB. Compared the HCPs of the SHGBs with ASHTCC and the T-shaped one, the MMTD of the former is reduced by $13.0 \%$. Thus, the structure of the ASHTCC is proven to be superior to that of the T-shaped one. The optimization results gained in this paper have reference values for the optimal structure designs for the heat dissipations of various electronic devices.
\end{abstract}

Keywords: constructal theory; arrow-shaped high thermal conductivity channel; maximum temperature difference minimization; multi-degree of freedom optimization; generalized thermodynamic optimization

\section{Introduction}

Nowadays, electronic information technology is developing rapidly. Many new electronic components are widely used in various aspects, such as national defense, industry, science and technology, and social life. At present, arranging the high thermal conductivity channel (HTCC) material is one of the common methods to dissipate the heat of the electronic component.

Bejan [1] stated the constructal law after further studying the formation of urban street networks, and applied it to the optimization of the heat dissipation structure of an electronic device (ED) [2]. Since the introduction of the constructal theory [3-23], it has been applied to design various heat dissipation bodies, such as rectangular [24-31], triangular [32-37], square [38-47] and discal [48-59] bodies, pin-fins [60,61], fork-shaped fins [62,63], generating heat plate [64,65], radiant enclosures [66,67], and heat storage systems [68] among others.

In the constructal designs of the square bodies, Lorenzini et al. [38] set up a heat conduction model (HCM) with X-shaped HTCC in a square heat generation body (SHGB), optimized the structure of 
X-shaped HTCC with minimum hot spot temperature (HST), and found that the X-shaped HTCC was evidently superior to the I-shaped one. Lorenzini et al. [38] further established a non-uniform HCM, and showed that the heat conduction performance (HCP) of the new HTCC was about $10 \%$ higher than that of the HTCC with uniform one. Hajmohammadi et al. [41,42] built the HCMs with three new HTCCs in the SHGBs, and found that their dimensionless maximum temperature differences (DMTDs) after constructal optimizations were lower than those with X- and I-shaped HTCCs. Feng et al. [43] set up an HCM with "+" shaped HTCC in an SHGB, and reduced the DMTD of the SHGB by $12.11 \%$ after the use of optimized HTCC with variable cross-section. Lorenzini et al. [44] established an I-shaped HTCC model in an SHGB, and effectively reduced the HST of the SHGB after constructal design. Konan and Cetkin [45] optimized the construct of a snowflake-shaped HTCC in an SHGB, and found that the optimal construct of the HTCC with minimum DMTD was very close to the shape of a snowflake in nature. Hajmohammadi and Rezaei [46] optimized the distributions of HTCCs with two branches in an SHGB based on a local recursive algorithm. The result displayed that the optimized HST was lower than those derived by most models of the discussed literature. Hajmohammadi et al. [47] built an HCM with multistage irregular dendritic HTCC in an SHGB, and found that the HCP was improved by up to $61 \%$ compared with the discussed optimal results in the literatures.

There are many possible geometry shapes of high thermal conductivity channels. The geometry shape of a high thermal conductivity channel has important effects of the heat conduction performance, and a more effective geometry shape is meaningful for engineering practice. Therefore, based on Refs. [38-47], an HCM with an arrow-shaped HTCC (ASHTCC) in an SHGB will be established in this paper. Aiming at the objective of DMTD, the construct of the ASHTCC in the SHGB will be optimized by using constructal theory. Single, two, and three degrees of freedom optimizations will be introduced and compared. The gained optimization results have reference values for the optimal structure designs for the heat dissipations of various electronic devices.

\section{Model Establishment}

The physical and mathematical models are established as follows, respectively.

\subsection{Physical Model}

Figure 1 shows the HCM of an ASHTCC in a square heat generation body. The side length of the SHGB is $L$. The heat generation rate per unit volume of the SHGB (thermal conductivity $k_{0}$ ) is $q^{\prime \prime \prime}$. The heat flows into the ASHTCC (thermal conductivity is $k_{p}$ ), and then flows out of the SHGB from the left side of the ASHTCC (constant temperature $T_{\min }$ ). The ratio of the thermal conductivities (TCs) is defined as $\widetilde{k}=k_{p} / k_{0}$. As shown in Figure 1, the ASHTCC is composed of a triangular arrow tip and rectangular arrow tail, the characteristic sizes of which are $L_{1}, L_{2}, H_{1}$, and $H_{2}$, respectively. It can be concluded that the temperature of each point in the area of SHGB is higher than that of $T_{\min }$. Except for the constant temperature at the left side of the ASHTCC, the other boundaries of the SHGB are all adiabatic.

The area $A_{0}$ of the ASHTCC can be expressed as: $A_{0}=H_{1} L_{1}+H_{2} L_{2}$. The whole area of the SHGB is $L^{2}$. The area ratio $\phi$ of the HTCC material to the SHGB is:

$$
\phi=\frac{H_{1} L_{1}+H_{2} L_{2}}{L^{2}}=\widetilde{H}_{1} \widetilde{L}_{1}+\widetilde{H}_{2} \widetilde{L}_{2}
$$

where $L_{1}, L_{2}, H_{1}$, and $H_{2}$ are nondimensionalized as: $\widetilde{L}_{1}=L_{1} / L, \widetilde{L}_{2}=L_{2} / L, \widetilde{H}_{1}=H_{1} / L$, and $\widetilde{H}_{2}=H_{2} / L$, respectively. 


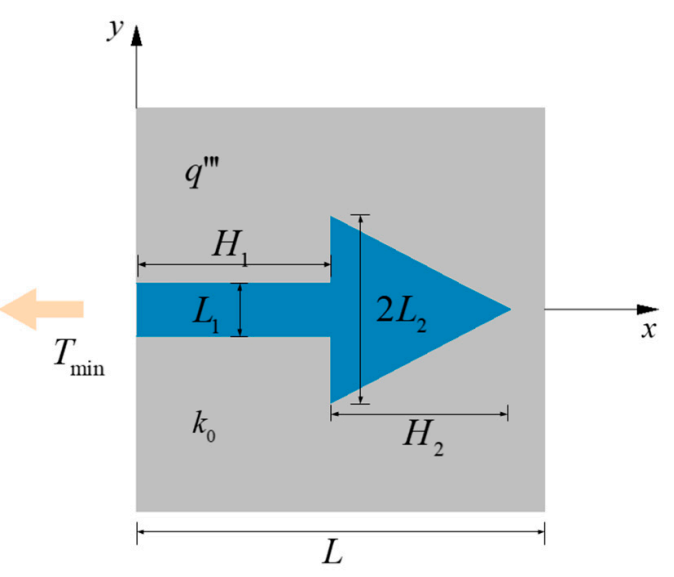

Figure 1. HCM of an ASHTCC in an SHGB.

\subsection{Mathematical Model}

Because the model in Figure 1 is symmetric with respect to the $Y$-axis, the temperature distributions will be equal to each other at both sides of the $Y$-axis. Therefore, only half of the geometry $(y \geq 0)$ will be simulated in the following. It is not a simple one-dimensional HCM due to the ASHTCC, thus a numerical calculation method should be adopted. The two-dimensional dimensionless heat conduction equations in a steady state and with constant thermal conductivity of the low and high TC materials are

$$
\begin{aligned}
& \frac{\partial^{2} \widetilde{T}}{\partial \widetilde{x}^{2}}+\frac{\partial^{2} \widetilde{T}}{\partial \widetilde{y}^{2}}+1=0 \\
& -\hat{k}\left(\frac{\partial^{2} \widetilde{T}}{\partial \widetilde{x}^{2}}+\frac{\partial^{2} \widetilde{T}}{\partial \widetilde{y}^{2}}\right)=0
\end{aligned}
$$

where $\widetilde{T}=\left(T-T_{\min }\right) /\left(q^{\prime \prime \prime} L^{2} / k_{0}\right), \widetilde{k}=k_{p} / k_{0}, \widetilde{x}=x / L$, and $\widetilde{y}=y / L$. The dimensionless boundary constraints in the $y \geq 0$ region are:

$$
\begin{gathered}
\widetilde{T}=0, \tilde{x}=0,0 \leq \widetilde{y}<\widetilde{L}_{1} / 2 \\
\frac{\partial \widetilde{T}}{\partial \widetilde{x}}=0 \quad \begin{cases}\widetilde{x}=0, & \widetilde{L}_{1} / 2 \leq \widetilde{y} \leq 1 / 2 \\
\widetilde{x}=1, & 0 \leq \widetilde{y} \leq 1 / 2\end{cases} \\
\frac{\partial \widetilde{T}}{\partial \widetilde{y}}=0 \quad \begin{cases}\widetilde{y}=0, & 0 \leq \widetilde{x} \leq 1 \\
\widetilde{y}=1 / 2, \quad 0 \leq \widetilde{x} \leq 1\end{cases}
\end{gathered}
$$

where $\widetilde{L}_{1}=L_{1} / L$.

Assuming that the contact thermal resistance between HTCC and low TC material is negligible, the continuity equation of heat flux between $k_{p}$ and $k_{0}$ materials is

$$
(\partial T / \partial n)_{k_{0}}=\widetilde{k}(\partial T / \partial n)_{k_{p}}
$$

The DMTD in the SHGB is defined as

$$
\Delta \widetilde{T}_{1}=\left(T_{\max }-T_{\min }\right) /\left(q^{\prime \prime \prime} L^{2} / k_{0}\right)
$$

where $T_{\max }$ is the HST in the SHGB.

The finite element software (Comsol Multiphysics) can be used to solve Equations (1)-(7). Combining with Equation (8), the DMTD can be obtained. Under the condition that the area ratio $\phi$ of the HTCC material in Equation (1) is given, the dimensionless height $\widetilde{H}_{2}$ of the arrow tip can 
be expressed by the dimensionless width $\widetilde{L}_{1}$ of the arrow tail, dimensionless bottom length $\widetilde{L}_{2}$ of the arrow tip, and dimensionless length $\widetilde{H}_{1}$ of the arrow tail. Finally, the DMTD is related to the structure parameters $\widetilde{L}_{1}, \widetilde{L}_{2}$ and $\widetilde{H}_{1}\left(\widetilde{L}_{1}=L_{1} / L, \widetilde{L}_{2}=L_{2} / L\right.$ and $\left.\widetilde{H}_{1}=H_{1} / L\right)$, respectively.

\section{Constructal Design of the ASHTCC}

Three degrees of freedom are considered in the constructal design problem of the ASHTCC. Constructal designs of the ASHTCC based on single, double, and three degrees of freedom optimizations will be successively conducted as follows. The initial parameters are set as follows: The constant temperature $T_{\min }=300 \mathrm{~K}$, the heat generation rate $q^{\prime \prime \prime}=500\left(\mathrm{~W} / \mathrm{m}^{3}\right)$, and the low thermal conductivity of materials $k_{0}=2(\mathrm{~W} / \mathrm{m} \cdot \mathrm{K})$.

\subsection{Constructal Design Based on Single Degree of Freedom Optimization}

For the fixed $\widetilde{L}_{2}$ and $\widetilde{H}_{1}$, the DMTD is selected as the performance index, and the constructal design of the ASHTCC is conducted by varying the width $\widetilde{L}_{1}$, i.e., single degree of freedom optimization (SDFO). The relevant parameters in the calculations are given as follows: the area ratio of the HTCC material is $\phi=0.1$, dimensionless bottom length is $\widetilde{L}_{2}=0.4$, dimensionless height is $\widetilde{H}_{2}=0.1$, and TC ratio is $\widetilde{k}_{0}=200$.

Figure 2 shows the influence of the TC ratio $\widetilde{k}$ on the relationship between the DMTD $\Delta \widetilde{T}_{1}$ and dimensionless width $\widetilde{L}_{1}$ of the ASHTCC with $\phi=0.1$. From Figure 2, under the conditions of area ratio $\phi=0.1$ and dimensionless arrow tip area $\widetilde{L}_{2} \widetilde{H}_{2}=0.04$, the minimum value of $\Delta \widetilde{T}_{1}$ can be obtained by selecting reasonable $\widetilde{L}_{1}$. When $\widetilde{L}_{1}$ is close to $\widetilde{L}_{1}=0.1$, the HCP of the SHGB is better. In addition, when $\widetilde{L}_{1}$ remains constant, $\Delta \widetilde{T}_{1}$ gradually decreases with the increase in $\widetilde{k}$. This illustrates that increasing the TC ratio can also improve the HCP of the SHGB.

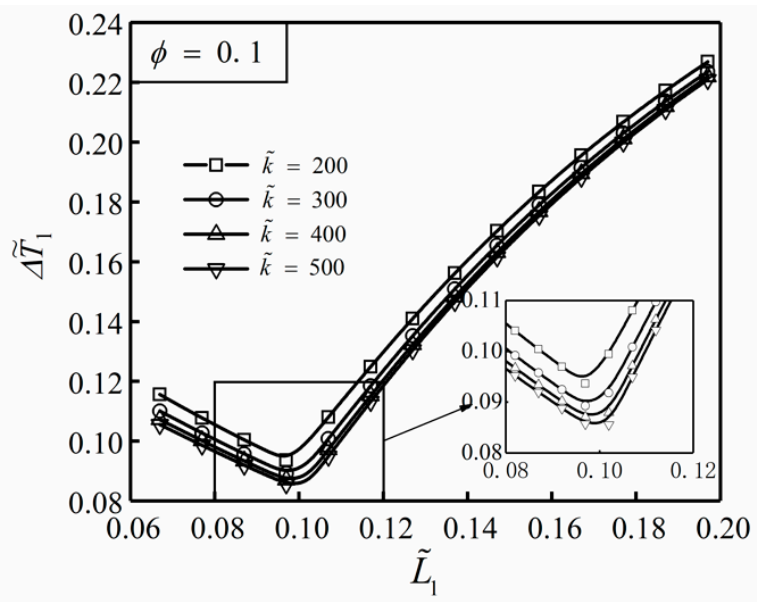

Figure 2. Influence of $\widetilde{k}$ on the relationship between $\Delta \widetilde{T}_{1}$ and $\widetilde{L}_{1}$ with $\phi=0.1$.

Figure 3 shows the influence of the area ratio $\phi$ of HTCC material on the relationship between the DMTD $\Delta \widetilde{T}_{1}$ and dimensionless width $\widetilde{L}_{1}$ of the ASHTCC with $\widetilde{k}=200$. When $\phi$ changes in a small range, the heat generation rate of the SHGB will slightly change, which is ignored in the following analyses. From Figure 3, it can be seen that when $\phi$ increases, the minimum value of the DMTD $\Delta \widetilde{T}_{1}$ decreases and $\widetilde{L}_{1, \text { opt }}$ increases gradually. This indicates that the larger the HTCC area is, the better the HCP of the SHGB becomes. For approximately the same heat generation rate of the SHGB, when the area ratio increases from $\phi=0.10$ to $\phi=0.13$, the minimum DMTD decreases by $20.21 \%$, and the HCP of the SHGB becomes better. When $\phi=0.1$ and $\widetilde{k}=300$, the minimum DMTD of the SHGB obtained by finite element method is $\Delta \widetilde{T}_{1, \mathrm{~m}}=0.088$, and the temperature profile corresponding to the optimal construct is shown in Figure 4. 


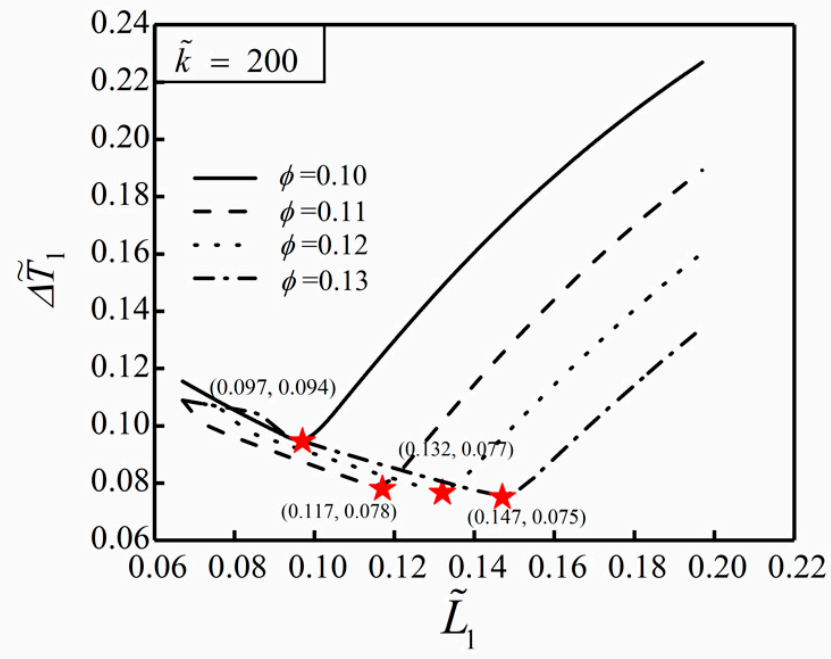

Figure 3. Influence of $\phi$ on the relationship between $\Delta \widetilde{T}_{1}$ and $\widetilde{L}_{1}$ with $\widetilde{k}=200$.

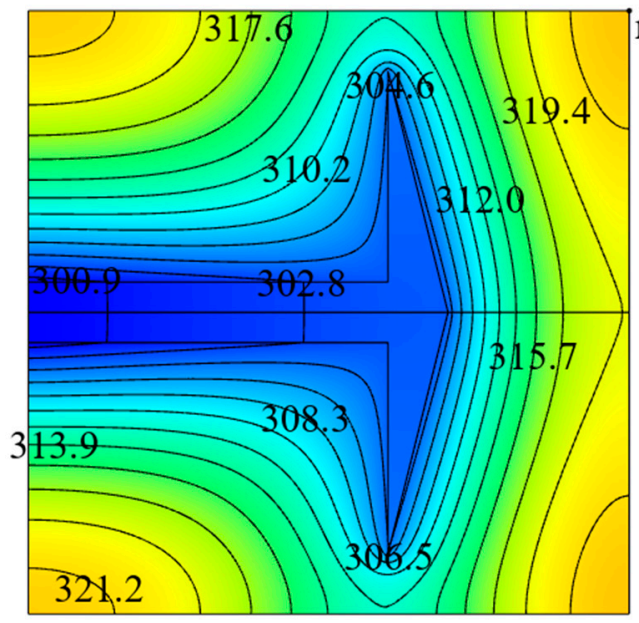

$\max : 322.2$

Figure 4. Temperature profile corresponding to the optimal construct based on SHGB.

\subsection{Constructal Design Based on Two Degrees of Freedom Optimization}

The dimensionless bottom length $\widetilde{L}_{2}$ and dimensionless length $\widetilde{H}_{1}$ are fixed in Section 3.1, and the constructal design of the ASHTCC will be conducted by varying the width $\widetilde{L}_{1}$ and bottom length $\widetilde{L}_{2}$ simultaneously in this section. In the two degrees of freedom optimization (TWDFO), the arrow tip area remains unchanged at $\widetilde{L}_{2} \widetilde{H}_{2}=0.04$.

Figure 5 shows the influences of TC ratio $\widetilde{k}$ on the optimal results $\left(\Delta \widetilde{T}_{1, \mathrm{~mm}}, \widetilde{L}_{1, \mathrm{opt}}\right.$ and $\left.\widetilde{L}_{2, \mathrm{opt}}\right)$ of TWDFO with $\phi=0.1$. From Figure 5, it can be seen that the optimal construct of the ASHTCC after TWDFO is $\widetilde{L}_{1, \text { opt }} \approx 0.1$ and $\widetilde{L}_{2, \text { opt }} \approx 0.499$. In this case, the HTCC shape becomes flat. When the TC ratio $\widetilde{k}$ increases, the changes of $\widetilde{L}_{1, \text { opt }}$ and $\widetilde{L}_{2, \text { opt }}$ are not obvious, while the double minimum DMTD $\Delta \widetilde{T}_{1, \mathrm{~mm}}$ decreases gradually. Figure 6 further shows the influences of the area ratio $\phi$ of HTCC material on the optimal results $\left(\Delta \widetilde{T}_{1, \mathrm{~mm}}, \widetilde{L}_{1, \mathrm{opt}}\right.$ and $\left.\widetilde{L}_{2, \mathrm{opt}}\right)$ of TWDFO with $\widetilde{k}=200$. According to Figure 6 , when the area ratio $\phi$ increases, the change of $\widetilde{L}_{2, \text { opt }}$ is not obvious, and $\widetilde{L}_{1 \text {,opt }}$ increases gradually, however $\Delta \widetilde{T}_{1, \mathrm{~mm}}$ decreases gradually. When $\phi=0.1$ and $\widetilde{k}=300$, the double minimum DMTD of the SHGB obtained by finite element method is $\Delta \widetilde{T}_{1, \mathrm{~mm}}=0.086$, and the temperature profile corresponding to the optimal construct is shown in Figure 7. 


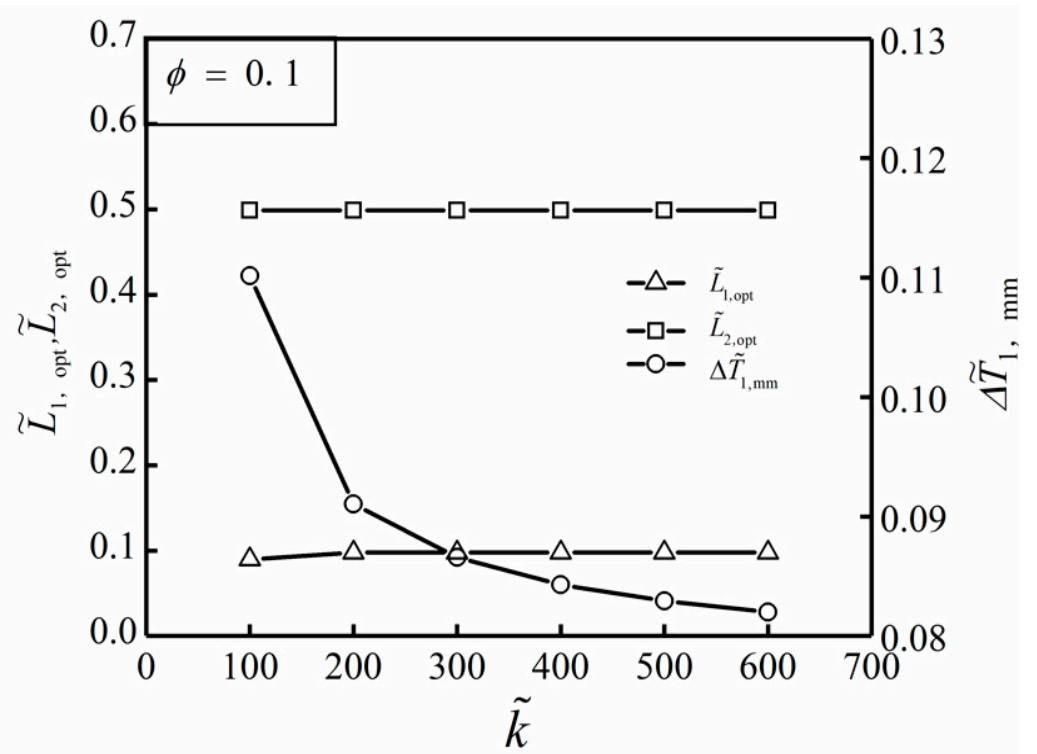

Figure 5. Influences of $\widetilde{k}$ on the optimal results of TWDFO with $\phi=0.1$.

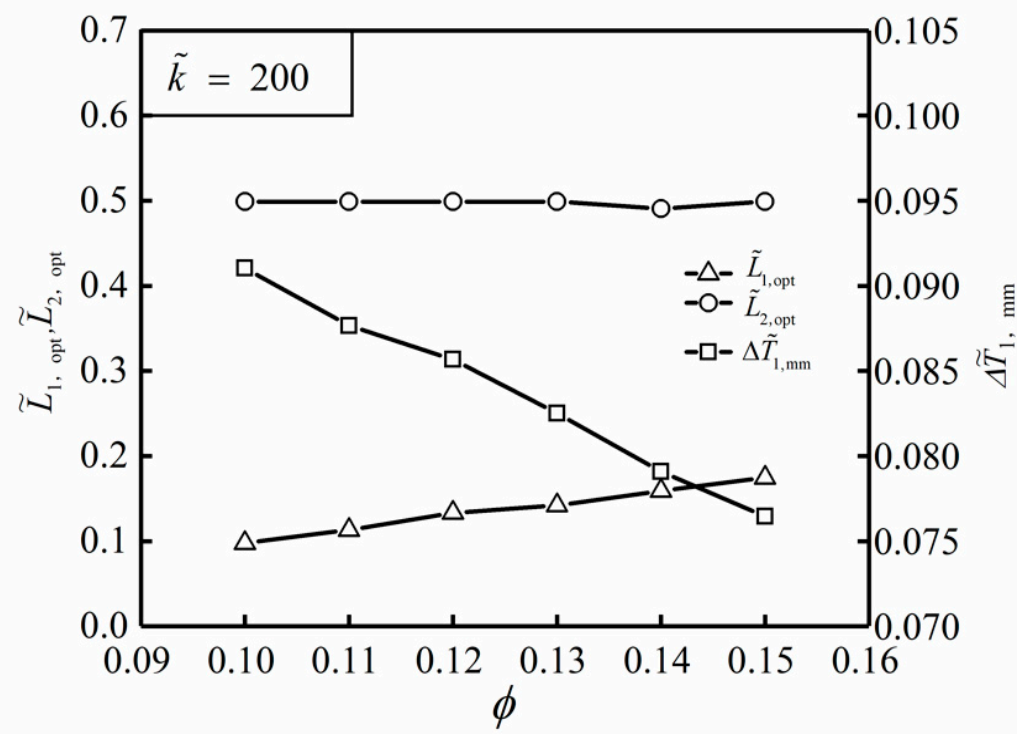

Figure 6. Influences of $\phi$ on the optimal results of TWDFO with $\widetilde{k}=200$. 


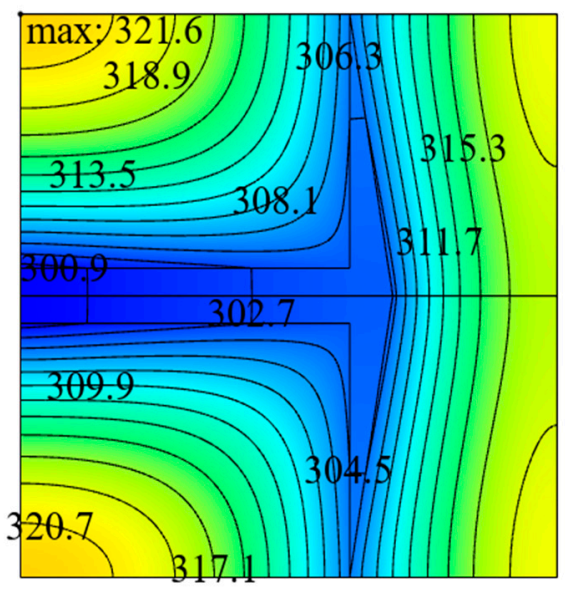

Figure 7. Temperature profile corresponding to the optimal construct based on TWDFO with $\widetilde{k}=300$ and $\phi=0.1$.

\subsection{Constructal Design Based on Three Degrees of Freedom Optimization}

The dimensionless length $\widetilde{H}_{1}$ is fixed in Section 3.2, and the constructal design of the ASHTCC will be further conducted by varying the width $\widetilde{L}_{1}$, bottom length $\widetilde{L}_{2}$, and dimensionless length $\widetilde{H}_{1}$ simultaneously in this section, i.e., the three degrees of freedom optimization (THDFO).

Figure 8 shows the influences of the TC ratio $\widetilde{k}$ on the optimal results $\left(\Delta \widetilde{T}_{1, \mathrm{mmm}}, \widetilde{L}_{1, \mathrm{opt}}, \widetilde{L}_{2, \mathrm{opt}}\right.$ and $\widetilde{H}_{1, \mathrm{opt}}$ ) of THDFO with $\phi=0.1$. From Figure 8 , it can be seen that the optimal construct of the ASHTCC after THDFO is $\widetilde{L}_{1, \mathrm{opt}}=0.197, \widetilde{L}_{2, \mathrm{opt}}=0.488$ and $\widetilde{H}_{1, \mathrm{opt}}=0.645$. This illustrates that the HCP of the SHGB is still better when the shape of the HTCC tends to be flat. When $\widetilde{k}$ increases, the changes of $\widetilde{L}_{1, \mathrm{opt}}, \widetilde{L}_{2, \mathrm{opt}}$, and $\widetilde{H}_{1, \mathrm{opt}}$ are not obvious, while the triple minimum DMTD $\Delta \widetilde{T}_{1, \mathrm{mmm}}$ decreases gradually. When the TC ratio increases from $\widetilde{k}=100$ to $\widetilde{k}=600$, the triple minimum DMTD decreases from $\Delta \widetilde{T}_{1, \mathrm{mmm}}=0.101$ to $\Delta \widetilde{T}_{1, \mathrm{mmm}}=0.079 . \Delta \widetilde{T}_{1, \mathrm{mmm}}$ is decreased by $21.8 \%$, and the HCP of the SHGB is significantly improved.

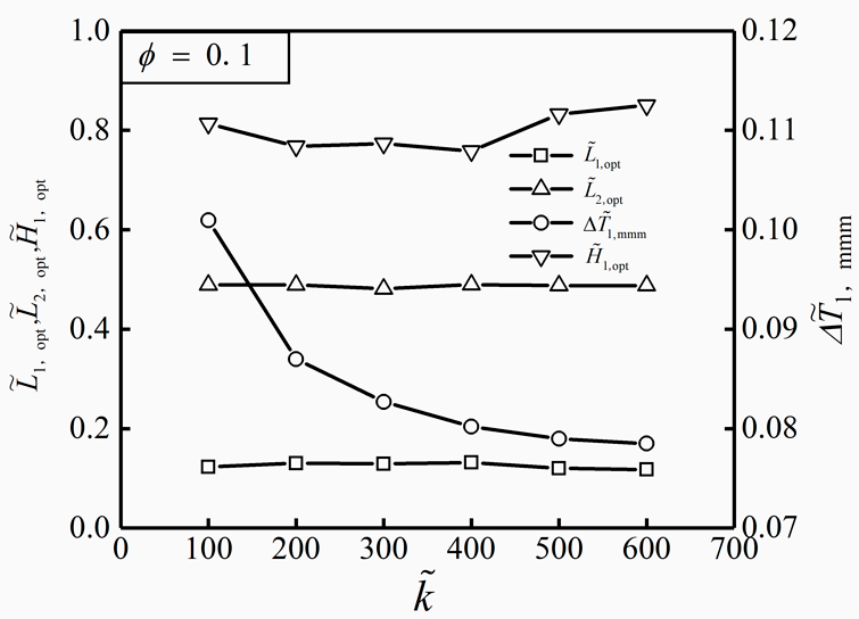

Figure 8. Influences of $\widetilde{k}$ on the optimal results of THDFO with $\phi=0.1$.

Figure 9 shows the influences of the area ratio $\phi$ on the optimal results $\left(\Delta \widetilde{T}_{1, \mathrm{mmm}}, \widetilde{L}_{1, \mathrm{opt}}, \widetilde{L}_{2, \mathrm{opt}}\right.$ and $\widetilde{H}_{1, \mathrm{opt}}$ ) of THDFO with $\phi=0.1$. From Figure 9, when the area ratio $\phi$ increases, the change of $\widetilde{L}_{2, \text { opt }}$ is not obvious, $\widetilde{L}_{1 \text {,opt }}$ increases gradually, and $\Delta \widetilde{T}_{1, \mathrm{mmm}}$ decreases gradually. When the area ratio increases from $\phi=0.10$ to $\phi=0.15$, the triple minimum DMTD decreases from $\Delta \widetilde{T}_{1, \mathrm{mmm}}=0.087$ to $\Delta \widetilde{T}_{1, \mathrm{mmm}}=0.074 . \Delta \widetilde{T}_{1, \mathrm{mmm}}$ is decreased by $14.9 \%$, and the HCP of the SHGB is significantly improved. 


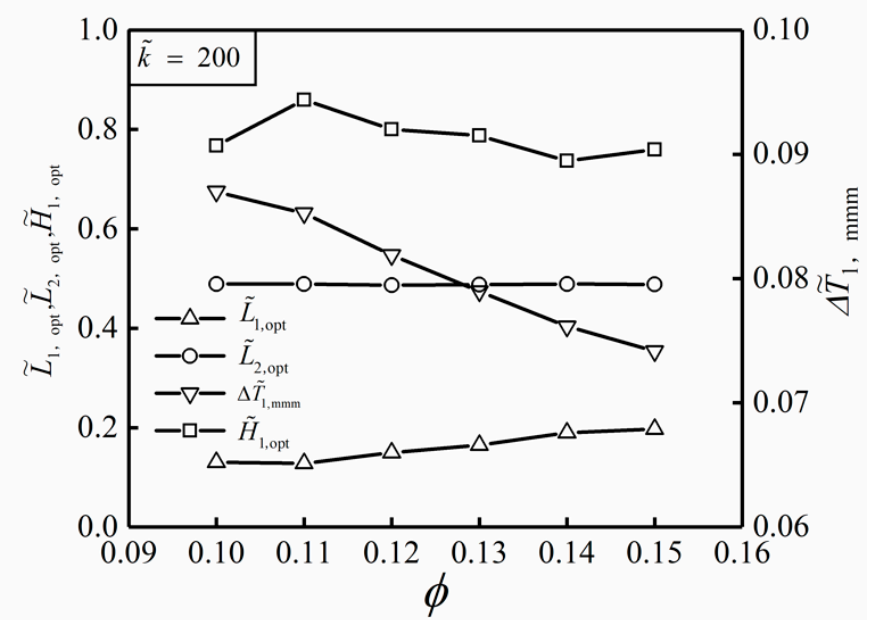

Figure 9. Influences of $\phi$ on the optimal results of THDFO with $\widetilde{k}=200$.

\subsection{Performance Comparison for Different Degrees of Freedom}

Under the conditions of $\phi=0.1$ and $\widetilde{k}=200$, the optimal constructs and corresponding temperature profiles of the ASHTCC obtained by single, double, and three degrees of freedom optimizations are shown in Figure 10, respectively. From the temperature profiles, it can be seen that the HSTs in the SHGBs are $323.7 \mathrm{~K}, 322.8 \mathrm{~K}$, and $321.7 \mathrm{~K}$, and the corresponding DMTDs are 0.095, 0.091 , and 0.087 , respectively. The DMTD of the SHGB after THDFO is respectively reduced by $4.40 \%$ and $8.42 \%$ compared with those after TWDFO and SDFO. It can be seen that the optimal structure of the ASHTCC obtained by THDFO significantly reduces the HST and improves the HCP of the SHGB.

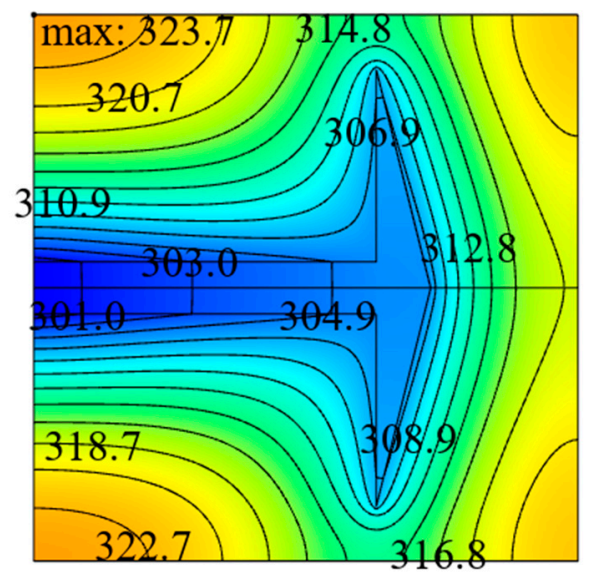

(a) SDFO

Figure 10. Cont. 


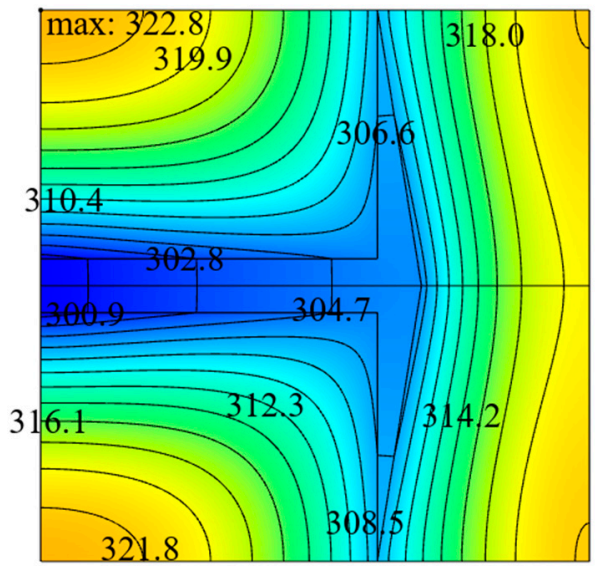

(b) TWDFO

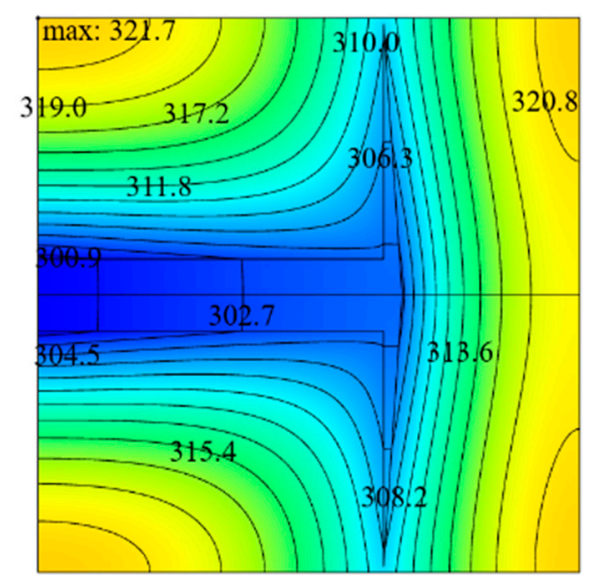

(c) THDFO

Figure 10. Temperature profiles corresponding to the optimal constructs obtained by single, double and three degrees of freedom optimizations with $\widetilde{k}=200$ and $\phi=0.1$.

4. Performance Comparison of the Square Heat Generation Bodies with Arrow- and T-Shaped High Thermal Conductivity Channels

To compare the HCP of the square heat generation body with ASHTCC to those with the other HTCCs, the optimal temperature profile of the SHGB with T-shaped HTCC is shown in Figure 11 as an example. From Figure 11, it can be seen that the triple minimum DMTD of the SHGB with T-shaped HTCC is $\Delta \widetilde{T}_{1, \mathrm{mmm}}=0.100$. Compared the HCP of the SHGB in Figure 10c with that in Figure 11, the DMTD of the former is reduced by $13.0 \%$. Therefore, the ASHTCC exhibits better HCP than the T-shaped HTCC. 


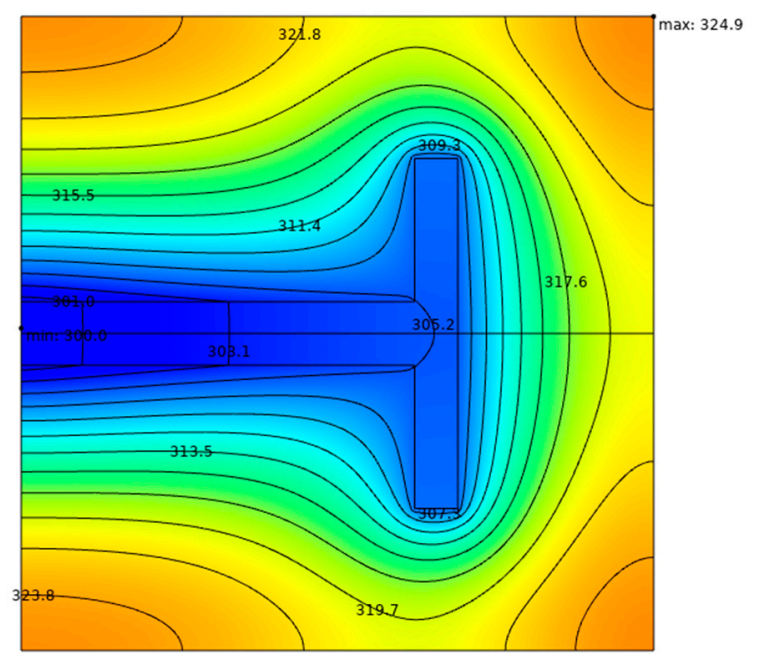

Figure 11. Optimal temperature profile of the SHGB with T-shaped HTCC, $\widetilde{k}=200$ and $\phi=0.1$.

\section{Conclusions}

A heat conduction model with ASHTCC in a square heat generation body is built in this paper. Constructal designs of the ASHTCC are conducted based on single, two, and three degrees of freedom optimizations with the objective of minimum DMTD. Optimal constructs of the ASHTCC and optimal temperature profiles are gained. The results are summarized as follows:

(1) For the SDFO, under the conditions of area ratio $\phi=0.1$ and dimensionless arrow tip area $\widetilde{L}_{2} \widetilde{H}_{2}=0.04$, when $\widetilde{L}_{1}$ is close to $\widetilde{L}_{1}=0.1$, the HCP of the SHGB is better. When the area ratio increases from $\phi=0.10$ to $\phi=0.13$, the minimum DMTD decreases by $20.21 \%$, and the HCP of the SHGB becomes better.

(2) For the TWDFO, the optimal construct of the ASHTCC is $\widetilde{L}_{1 \text {,opt }} \approx 0.1$ and $\widetilde{L}_{2, \text { opt }} \approx 0.499$. In this case, the shape of the HTCC becomes flat. When the TC ratio $\widetilde{k}$ increases, the changes of $\widetilde{L}_{1, \mathrm{opt}}$ and $\widetilde{L}_{2, \text { opt }}$ are not obvious, while the double minimum DMTD $\Delta \widetilde{T}_{1, \mathrm{~mm}}$ decreases gradually. When the area ratio $\phi$ increases, the change of $\widetilde{L}_{2, \text { opt }}$ is not obvious, and $\widetilde{L}_{1 \text {,opt }}$ increases gradually, however $\Delta \widetilde{T}_{1, \mathrm{~mm}}$ decreases gradually.

(3) For the THDFO, the optimal construct of the ASHTCC is $\widetilde{L}_{1, \mathrm{opt}}=0.197, \widetilde{L}_{2, \mathrm{opt}}=0.488$ and $\widetilde{H}_{1, \mathrm{opt}}=0.645$. This illustrates that the HCP of the SHGB is still better when the shape of the HTCC tends to be flat. The DMTD of the SHGB after THDFO is respectively reduced by $4.40 \%$ and $8.42 \%$ compared with those after TWDFO and SDFO.

(4) Comparing the HCP of the SHGB in Figure 10c with that in Figure 11, the DMTD of the former is reduced by $13.0 \%$. Therefore, the ASHTCC exhibits better HCP than the T-shaped HTCC.

In this paper, the construct of an elemental ASHTCC in the SHGB is optimized. The first-order ASHTCC can be composed of several elemental ASHTCCs. At the same time, the arc structure can be used to replace the cusp structure at the arrow tip. The constructal optimizations of the HTCCs in the SHGB will be further conducted in our future studies by considering the additional model improvements, and better HCPs of the electronic devices will be obtained. Moreover, other optimization objectives, such as entropy generation minimization [69-75], will also be conducted.

Author Contributions: Conceptualization, L.C. and H.F.; methodology, F.Z.; software, F.Z., H.F., J.Y., and Z.X.; validation, F.Z., H.F., J.Y., and Z.X.; writing-original draft preparation, F.Z. and H.F.; writing-review and editing, L.C.; supervision, L.C.; funding acquisition, L.C. and Z.X. All authors have read and agreed to the published version of the manuscript.

Funding: This work is supported by the National Natural Science Foundation of China (Grant Nos. 51779262 and 51979278) and Independent Project of Naval University of Engineering (No. 425317Q017). 
Acknowledgments: The authors wish to thank the reviewers for their careful, unbiased and constructive suggestions, which led to this revised manuscript.

Conflicts of Interest: The authors declare no conflict of interest.

\section{Abbreviations}

$\begin{array}{ll}\text { ASHTCC } & \text { Arrow-shaped high thermal conductivity channel } \\ \text { DMTD } & \text { Dimensionless maximum temperature difference } \\ \text { HCM } & \text { Heat conduction model } \\ \text { HCP } & \text { Heat conduction performance } \\ \text { HST } & \text { Hot spot temperature } \\ \text { HTCC } & \text { High thermal conductivity channel } \\ \text { SDFO } & \text { Single degree of freedom optimization } \\ \text { SHGB } & \text { Square heat generation body } \\ \text { TC } & \text { Thermal conductivity } \\ \text { TWDFO } & \text { Two degrees of freedom optimization } \\ \text { THDFO } & \text { Three degrees of freedom optimization } \\ \text { Nomenclature } & \\ A_{0} & \text { Area, m }{ }^{2} \\ k & \text { Thermal conductivity, W/m/K } \\ \widetilde{k} & \text { Ratio of the thermal conductivity } \\ L & \text { Side length of the SHGB, } \mathrm{m} \\ L_{1}, L_{2}, H_{1}, H_{2} & \text { Characteristic sizes of the ASHTCC, } \mathrm{m} \\ L_{1}, \widetilde{L}_{2}, \widetilde{H}_{1}, \widetilde{H}_{2} & \text { Nondimensional characteristic sizes of the ASHTCC } \\ T & \text { Temperature, K } \\ q^{\prime \prime \prime} & \text { Heat generation rate in the SHGB, W/m }{ }^{3} \\ \phi & \text { Area ratio of the HTCC }\end{array}$

\section{References}

1. Bejan, A. Street network theory of organization in nature. J. Adv. Transp. 1996, 30, 85-107. [CrossRef]

2. Bejan, A. Constructal-theory network of conducting paths for cooling a heat generating volume. Int. J. Heat Mass Transf. 1997, 40, 799-816. [CrossRef]

3. Bejan, A. Shape and Structure, from Engineering to Nature; Cambridge University Press: Cambridge, UK, 2000.

4. Bejan, A.; Lorente, S. Thermodynamic optimization of flow geometry in mechanical and civil engineering. J. Non-Equilib. Thermodyn. 2001, 26, 305-354. [CrossRef]

5. Bejan, A.; Marden, J.H. Constructing animal locomotion from new thermodynamics theory. Am. Sci. 2006, 94, 342-349. [CrossRef]

6. Kim, S.; Lorente, S.; Bejan, A. Design with Constructal Theory: Vascularized Composites for Volumetric Cooling; ASME International: New York, NY, USA, 2008; pp. 437-444.

7. Chen, L. Progress in study on constructal theory and its applications. Sci. China Ser. E Technol. Sci. 2012, 55, 802-820. [CrossRef]

8. Feng, H.; Chen, L.; Xie, Z.; Sun, F. Constructal entropy generation rate minimization for X-shaped vascular networks. Int. J. Therm. Sci. 2015, 92, 129-137. [CrossRef]

9. Bejan, A. Constructal thermodynamics. Int. J. Heat Technol. 2016, 34. [CrossRef]

10. Chen, L.; Feng, H.; Xie, Z. Generalized thermodynamic optimization for iron and steel production processes: Theoretical exploration and application cases. Entropy 2016, 18, 353. [CrossRef]

11. Chen, L.G.; Feng, H.J. Multi-Objective Constructal Optimizations for Fluid Flow, Heat and Mass Transfer Processes; Science Press: Beijing, China, 2016.

12. Feng, H.; Chen, L.; Xie, Z. Multi-disciplinary, multi-objective and multi-scale constructal optimizations for heat and mass transfer processes performed in naval university of engineering, a review. Int. J. Heat Mass Transf. 2017, 115, 86-98. [CrossRef]

13. Bejan, A. Evolution in thermodynamics. Appl. Phys. Rev. 2017, 4, 011305. [CrossRef] 
14. Chen, L.; Liu, X.; Feng, H.; Ge, Y.; Xie, Z. Molten steel yield optimization of a converter based on constructal theory. Sci. China Ser. E Technol. Sci. 2017, 61, 496-505. [CrossRef]

15. Bejan, A. Constructal law, twenty years after. Proc. Rom. Acad. Ser. A Math. Phys. Tech. Sci., Inf. Sci. 2018, 18, 309-311.

16. Chen, L.; Xiao, Q.; Feng, H. Constructal optimizations for heat and mass transfers based on the entransy dissipation extremum principle, performed at the naval university of engineering: A review. Entropy 2018, 20, 74. [CrossRef]

17. Chen, L.; Feng, H.; Xie, Z.; Sun, F. Progress of constructal theory in China over the past decade. Int. J. Heat Mass Transf. 2019, 130, 393-419. [CrossRef]

18. Lorente, S.; Bejan, A. Current trends in constructal law and evolutionary design. Heat Transf. Asian Res. 2019, 48, 3574-3589. [CrossRef]

19. Feng, H.; Chen, L.; Xie, Z. Constructal entransy dissipation rate minimization for X-shaped vascular networks. Sci. China Ser. E Technol. Sci. 2019, 62, 2195-2203. [CrossRef]

20. Bejan, A. Freedom and Evolution; Springer Science and Business Media LLC: Berlin, Germany, 2020.

21. You, J.; Feng, H.; Chen, L.; Xie, Z.; Xia, S. Constructal design and experimental validation of a non- uniform heat generating body with rectangular cross-section and parallel circular cooling channels. Int. J. Heat Mass Transf. 2020, 148, 119028. [CrossRef]

22. Wu, Z.; Feng, H.; Chen, L.; Tang, W.; Shi, J.; Ge, Y. Constructal thermodynamic optimization for ocean thermal energy conversion system with dual-pressure organic Rankine cycle. Energy Convers. Manag. 2020, 210, 112727. [CrossRef]

23. Chen, L.G.; Yang, A.B.; Feng, H.J.; Ge, Y.L.; Xia, S.J. Constructal designs for eight types of heat sinks. Sci. China Technol. Sci. 2020. [CrossRef]

24. Dan, N.; Bejan, A. Constructal tree networks for the time-dependent discharge of a finite-size volume to one point. J. Appl. Phys. 1998, 84, 3042-3050. [CrossRef]

25. Wu, W.; Chen, L.; Sun, F. On the "area to point" flow problem based on constructal theory. Energy Convers. Manag. 2007, 48, 101-105. [CrossRef]

26. Wei, S.H.; Chen, L.G.; Sun, F.R. The volume-point constructal optimization for discrete variable cross-section conducting path. Appl. Energy 2009, 86, 1111-1118. [CrossRef]

27. Marck, G.; Harion, J.-L.; Nemer, M.; Russeil, S.; Bougeard, D. A new perspective of constructal networks cooling a finite-size volume generating heat. Energy Convers. Manag. 2011, 52, 1033-1046. [CrossRef]

28. Cetkin, E.; Oliani, A. The natural emergence of asymmetric tree-shaped pathways for cooling of a non-uniformly heated domain. J. Appl. Phys. 2015, 118, 024902. [CrossRef]

29. Feng, H.; Chen, L.; Xie, Z.; Sun, F. Constructal design for a rectangular body with nonuniform heat generation. Eur. Phys. J. Plus 2016, 131, 274. [CrossRef]

30. Lorenzini, G.; Biserni, C.; Dalpiaz, F.L.; Fagundes, T.M.; Rocha, L.A.O. Geometric optimization of T-shaped constructs coupled with a heat generating basement: A numerical approach motivated by Bejan's constructal theory. J. Eng. 2017, 26, 485-497. [CrossRef]

31. Fagundes, T.M.; Lorenzini, G.; Estrada, E.D.S.D.; Isoldi, L.A.; Dos Santos, E.D.; Rocha, L.A.O.; Neto, A.J.S. Constructal design of conductive asymmetric Tri-Forked pathways. J. Eng. 2019, 28, 26-42. [CrossRef]

32. Ghodoossi, L.; Eğrican, N. Exact solution for cooling of electronics using constructal theory. J. Appl. Phys. 2003, 93, 4922. [CrossRef]

33. Ghodoossi, L.; Eğrican, N. Conductive cooling of triangular shaped electronics using constructal theory. Energy Convers. Manag. 2004, 45, 811-828. [CrossRef]

34. Chen, L.; Wu, W.; Sun, F. Constructal re-optimization of heat conduction with the triangular elemental area. Int. J. Low-Carbon Technol. 2012, 9, 256-261. [CrossRef]

35. Feng, H.; Chen, L.; Xie, Z.; Sun, F. "Volume-point" heat conduction constructal optimization based on minimization of maximum thermal resistance with triangular element at micro and nanoscales. J. Energy Inst. 2016, 89, 302-312. [CrossRef]

36. You, J.; Feng, H.; Chen, L.; Xie, Z. Heat conduction constructal optimization for nonuniform heat generating area based on triangular element. Int. J. Heat Mass Transf. 2018, 117, 896-902. [CrossRef]

37. You, J.; Feng, H.; Chen, L.; Xie, Z. Constructal design of nonuniform heat generating area based on triangular elements: A case of entropy generation minimization. Int. J. Therm. Sci. 2019, 139, 403-412. [CrossRef] 
38. Lorenzini, G.; Biserni, C.; Rocha, L. Constructal design of X-shaped conductive pathways for cooling a heat-generating body. Int. J. Heat Mass Transf. 2013, 58, 513-520. [CrossRef]

39. Cetkin, E. Constructal structures with and without high-conductivity inserts for self- cooling. Int. J. Heat Technol. 2016, 34, S37-S42.

40. Lorenzini, G.; Biserni, C.; Rocha, L. Constructal design of non-uniform X-shaped conductive pathways for cooling. Int. J. Therm. Sci. 2013, 71, 140-147. [CrossRef]

41. Hajmohammadi, M.; Shariatzadeh, O.J.; Moulod, M.; Nourazar, S. Phi and Psi shaped conductive routes for improved cooling in a heat generating piece. Int. J. Therm. Sci. 2014, 77, 66-74. [CrossRef]

42. Hajmohammadi, M.R.; Lorenzini, G.; Shariatzadeh, O.J.; Biserni, C. Evolution in the design of V-shaped highly conductive pathways embedded in a heat-generating piece. J. Heat Transf. 2015, 137, 061001. [CrossRef]

43. Feng, H.J.; Chen, L.G.; Xie, Z.H.; Sun, F.R. Constructal design for "+" shaped high conductive pathways over a square body. Int. J. Heat Mass Transf. 2015, 91, 162-169. [CrossRef]

44. Lorenzini, G.; Barreto, E.; Beckel, C.; Schneider, P.S.; Isoldi, L.A.; Dos Santos, E.; Rocha, L.; Dos Santos, E.D. Constructal design of I-shaped high conductive pathway for cooling a heat-generating medium considering the thermal contact resistance. Int. J. Heat Mass Transf. 2016, 93, 770-777. [CrossRef]

45. Konan, H.; Cetkin, E. Snowflake shaped high-conductivity inserts for heat transfer enhancement. Int. J. Heat Mass Transf. 2018, 127, 473-482. [CrossRef]

46. Hajmohammadi, M.; Rezaei, E. Proposing a new algorithm for the optimization of conduction pathways based on a recursive localization. Appl. Eng. 2019, 151, 146-153. [CrossRef]

47. Hajmohammadi, M.; Parsa, H.; Najafian, J. Proposing an optimal tree-like design of highly conductive material configuration with unequal branches for maximum cooling a heat generating piece. Int. J. Heat Mass Transf. 2019, 142, 118422. [CrossRef]

48. Rocha, L.; Lorente, S.; Bejan, A. Constructal design for cooling a disc-shaped area by conduction. Int. J. Heat Mass Transf. 2002, 45, 1643-1652. [CrossRef]

49. Rocha, L.; Lorente, S.; Bejan, A. Conduction tree networks with loops for cooling a heat generating volume. Int. J. Heat Mass Transf. 2006, 49, 2626-2635. [CrossRef]

50. Salimpour, M.R.; Sharifi, F.; Menbari, D. Constructal design for cooling a disc-shaped body using incomplete inserts with temperature-dependent thermal conductivities. Proc. Inst. Mech. Eng. Part E J. Process. Mech. Eng. 2011, 227, 231-242. [CrossRef]

51. Xiao, Q.Y.; Chen, L.G.; Sun, F.R. Constructal optimization for "disc-to-point" heat conduction without the premise of optimized last-order construct. Int. J. Therm. Sci. 2011, 50, 1031-1036. [CrossRef]

52. Chen, L.G.; Feng, H.J.; Xie, Z.H.; Sun, F.R. Constructal optimization for "disc-point" heat conduction at micro and nanoscales. Int. J. Heat Mass Transf. 2013, 67, 704-711. [CrossRef]

53. Daneshi, M.; Zare, M.; Salimpour, M.R. Micro and nano-scale conductive tree-structures for cooling a disc-shaped electronic piece. Trans. ASME J. Heat Transf. 2013, 135, 031401. [CrossRef]

54. Bahadormanesh, N.; Salimpour, M.R. Constructal design of high-emissivity radiation inserts embedded in a disc-shaped heat generation body. Appl. Therm. Eng. 2016, 112, 638-648. [CrossRef]

55. Sharfi, F.; Salimpuor, R.M.; Campo, A. Cooling a solid disc with uniform heat generation using inserts of high thermal conductivity within the constructal design platform. Int. J. Therm. Environ. Eng. 2016, 12, 15-26.

56. You, J.; Feng, H.J.; Chen, L.G.; Xie, Z.H. Constructal optimization for cooling a non-uniform heat generating radial-pattern disc by conduction. Entropy 2018, 20, 685. [CrossRef]

57. Chen, L.G.; You, J.; Feng, H.J.; Xie, Z.H. Constructal optimization for "disc-point" heat conduction with nonuniform heat generating. Int. J. Heat Mass Transf. 2019, 134, 1191-1198. [CrossRef]

58. Liu, H.; Li, B.; Hong, J. Generating constructal-conduction-networks for cooling discs at macro and micro scales. Int. Commun. Heat Mass Transf. 2019, 109, 104318. [CrossRef]

59. Feng, H.J.; You, J.; Chen, L.G.; Ge, Y.L.; Xia, S.J. Constructal design of a non-uniform heat generating disc based on entropy generation minimization. Eur. Phys. J. Plus 2020, 135, 1-19. [CrossRef]

60. Chen, L.G.; Yang, A.B.; Xie, Z.H.; Sun, F.R. Constructal entropy generation rate minimization for cylindrical pin-fin heat sinks. Int. J. Therm. Sci. 2017, 111, 168-174. [CrossRef]

61. Mustafa, A.W. Constructal design of multi-scale diamond-shaped pin fins cooled by mixed convection. Int. J. Therm. Sci. 2019, 145, 106018. [CrossRef] 
62. Hazarika, S.A.; Bhanja, D.; Nath, S. A novel optimal constructal fork-shaped fin array design to ascertain thermo-heightened performance under dehumidifying conditions. Int. J. Therm. Sci. 2019, 144, 67-78. [CrossRef]

63. Hazarika, S.A.; Deshmukhya, T.; Bhanja, D.; Nath, S. A novel optimum constructal fork-shaped fin array design for simultaneous heat and mass transfer application in a space-constrained situation. Int. J. Therm. Sci. 2020, 150, 106225. [CrossRef]

64. Ribeiro, P.; Queiros-Condé, D. The space and time behaviour of the constructal plate generating heat. Int. J. Therm. Sci. 2019, 135, 173-186. [CrossRef]

65. Ribeiro, P.; Queiros-Condé, D. On the entropy production of the elemental construct of the constructal designed plate generating heat. Int. J. Therm. Sci. 2019, 145, 106043. [CrossRef]

66. Haratian, M.; Amidpour, M.; Hamidi, A.A. Conceptual development of constructal theory towards optimum sizing of radiant enclosures. Int. J. Therm. Sci. 2019, 137, 337-342. [CrossRef]

67. Mosa, M.; Labat, M.; Lorente, S. Cnstructal design of flow channels for radiant cooling panels. Int. J. Therm. Sci. 2019, 145, 106052. [CrossRef]

68. Joshi, V.; Rathod, M.K. Constructal enhancement of thermal transport in latent heat storage systems assisted with fins. Int. J. Therm. Sci. 2019, 145, 105984. [CrossRef]

69. Shi, H.N.; Xie, Z.H.; Chen, L.G.; Sun, F.R. Constructal optimization for line-to-line vascular based on entropy generation minimization principle. Int. J. Heat Mass Transf. 2018, 126, 848-854. [CrossRef]

70. Wu, Z.X.; Chen, L.G.; Feng, H.J. Thermodynamic optimization for an endoreversible Dual-Miller cycle (DMC) with finite speed of piston. Entropy 2018, 20, 165. [CrossRef]

71. Zhang, L.; Chen, L.G.; Xia, S.J.; Wang, C.; Sun, F.R. Entropy generation minimization for Reverse Water Gas Shift (RWGS) reactors. Entropy 2018, 20, 415. [CrossRef]

72. Chen, L.G.; Zhang, L.; Xia, S.J.; Sun, F.R. Entropy generation minimization for CO2 hydrogenation to light olefins. Energy 2018, 147, 187-196. [CrossRef]

73. Li, P.L.; Chen, L.G.; Xia, S.J.; Zhang, L. Entropy generation rate minimization for methanol synthesis via a $\mathrm{CO} 2$ hydrogenation reactor. Entropy 2019, 21, 174. [CrossRef]

74. Zhang, L.; Xia, S.J.; Chen, L.G.; Ge, Y.L.; Wang, C.; Feng, H.J. Entropy generation rate minimization for hydrocarbon synthesis reactor from carbon dioxide and hydrogen. Int. J. Heat Mass Transf. 2019, 137, 1112-1123. [CrossRef]

75. Li, P.L.; Chen, L.G.; Xia, S.J.; Zhang, L.; Kong, R.; Ge, Y.L.; Feng, H.J. Entropy generation rate minimization for steam methane reforming reactor heated by molten salt. Energy Rep. 2020, 6, 685-697. [CrossRef] 